\title{
DIFICULDADES, REFLEXÕES E POSSIBILIDADES NO ENSINO DA HISTÓRIA DA MÚSICA NO BRASIL DO NOSSO TEMPO
}

Paulo Castagna

\begin{abstract}
"E assim pensei que as ciências dos livros, ao menos aquelas cujas razões são apenas prováveis e que não apresentam quaisquer demonstrações, pois foram compostas e avolumadas devagar com opiniões de muitas e diferentes pessoas, não se encontram, de forma alguma, tão próximas da verdade quanto os simples raciocínios que um homem de bom senso pode fazer naturalmente acerca das coisas que se Ihe apresentam."

"[...] convenci-me de que não seria razoável que um particular tencionasse [...] reformar o corpo das ciências ou a ordem estabelecida nas escolas para ensiná-las; [...] o melhor a fazer seria dispor-me, de uma vez para sempre, a retirar-lhes essa confiança, para substituí-las em seguida ou por outras melhores, ou então pelas mesmas, após havê-las ajustado ao nível da razão."
\end{abstract}

René Descartes (Discurso sobre o método, 1637)

\section{Resumo}

Este artigo visa contribuir para a discussão sobre as necessárias mudanças no conceito, título e conteúdo das disciplinas "História da Música" e similares, destinadas ao aumento de sua eficiência no ensino musical da atualidade. Para esse objetivo, aborda-se o possível declínio da função do título e do conceito dessa disciplina na atualidade, propondo-se o título mais aberto de "Música, História, Cultura e Sociedade". 0 artigo também discute a relação entre autor e professor, e entre disciplinas obrigatórias e optativas, destacando a urgência, na área de Música, de uma reforma curricular (especialmente da disciplina em questão) voltada às necessidades atuais.

\section{Palavras-Chave:}

História da Música; Ensino; Reforma Curricular; Cultura; Sociedade.

\section{Abstract}

This article aims to contribute to the discussion about the necessary changes in the concept, title and content of the course "History of Music" and other similar courses, in order to increase its efficiency in the music education of our time. For this purpose, the text approaches the possible decline of the function of the title and the concept of this course in the present time, proposing the more opened title "Music, History, Culture and Society". The article also discusses the relationship between author and teacher, and between compulsory courses and optional courses, highlighting the urgency of the curriculum reform in the Music area (especially in History of Music) intended to the current needs.

\section{Keywords:}

History of Music; Education; Curriculum Reform; Culture; Society 


\section{Introdução}

Este artigo parte da observação pessoal de problemas práticos relacionados ao ensino de História da Música e levanta a hipótese de que tais dificuldades estejam principalmente relacionadas à manutenção - na bibliografia e na estruturação desses cursos - de visões de mundo defasadas da vida contemporânea, arriscando a apresentação de algumas possibilidades, mesmo que resultantes de livre reflexão. $O$ assunto não é novo e as soluções não são simples, por isso o objetivo deste artigo não é chegar a uma solução fechada, mas sim estimular o debate para a obtenção de soluções mais amplas e eficientes. Originalmente, o presente texto foi elaborado para ser apresentado em outubro de 2013 como projeto para a solicitação de mudanças estruturais nos cursos de História da Música no Instituto de Artes da UNESP - Universidade Estadual Paulista, porém foi reduzido e transformado na presente versão, para facilitar sua circulação e discussão no meio musical acadêmico.

\section{História da Música: título e conceito em de- clínio?}

Nos 25 anos nos quais venho ministrando a disciplina "História da Música" (20 deles no Instituto de Artes da UNESP), tenho percebido uma progressiva e acentuada diminuição do interesse e da aplicação do seu conteúdo junto aos estudantes, particularmente aqueles interessados na atuação musical prática, para quem os assuntos em questão vêm se mostrando cada vez mais desconectados de suas atividades pessoais e profissionais na área de Música. "História da Música" e "História da Música Brasileira" são hoje disciplinas frequentes nos currículos institucionais, mas com dificuldades de atender às necessidades dos estudantes da atualidade, geralmente múltiplas e diversificadas.

Causa particular dificuldade, aos alunos, a defasagem entre seus interesses e as prescrições da bibliografia ou dos profissionais que se dedicam a esse tipo de curso. Um dos fatores responsáveis é o título totalizante da disciplina e sua bibliografia - "história da música", ou seja, de toda a música - frente à abordagem quase exclusiva da música europeia de concerto. Essa concentração da abordagem da música europeia, em uma disciplina denominada "história da música", muitas vezes é entendida como afirmação eurocêntrica e aversão deliberada às culturas populares e repertórios não -eruditos - ainda que não seja esse o caso - surgindo em classe associações até mesmo com o controle social e a superposição das preferências pessoais ou institucionais aos interesses coletivos.

Embora não expressem a complexidade da circulação e da relação contemporânea com os distintos tipos de música e sua procedência, os dados sobre o mercado fonográfico atual fornecem indícios interessantes para se avaliar o impacto - ao menos quantitativo - da música de concerto no presente. De acordo com os relatórios da ASSOCIAÇÃO BRASILEIRA DOS PRODUTORES DE DISCOS (2012), que disponibiliza o faturamento do mercado fonográfico, desde $2000^{1}$, a vendagem dos "clássicos", como tem sido denominada toda a música que também denominamos "erudita" ou "de concerto", oscilou, nessa fase, de 1,3\% a 3,4\% do total, números já posteriores ao reequilíbrio de vendas após o primeiro impacto da pirataria e do download eletrônico, na década de 1990. No Gráfico 1 podemos observar a variação da porcentagem dos "clássicos" entre os anos de 2007 e 2012 e observar sua oscilação em torno de $2,5 \%$.

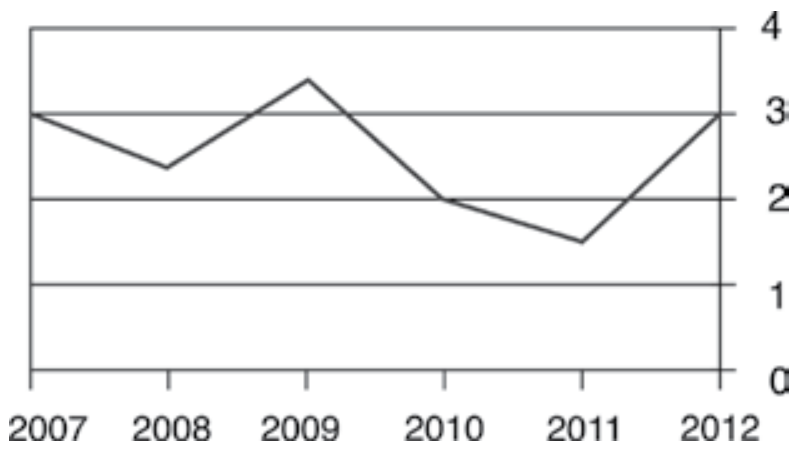

Gráfico 1. Porcentagem da venda de "clássicos" no faturamento anual total da indústria fonográfica brasileira entre 2007-2012, de acordo com dados da Associação Brasileira dos Produtores de Discos, disponíveis em: http://www.abpd.org.br/.

É fundamental mencionar, no entanto, que, em meio a esses cerca de $2,5 \%$ de "clássicos", foram computadas gravações de obras, autores ou intérpretes nem sempre tratados como centrais no meio acadêmico, além de toda a música contemporânea e a música brasileira de concerto (dos séculos XVIII a XXI), o que aponta para o fato de que esses números estão superestimados, no que se 
refere ao repertório estudado no meio acadêmico. Uma análise do mercado internacional demonstra uma oscilação quantitativa ainda mais complexa, porém uma situação não mais otimista que a do mercado fonográfico brasileiro. Do ponto de vista qualitativo, as transformações das últimas décadas configuraram um panorama muito diferente daquele no qual se desenvolveu a maior parte da música de concerto que chegou até o presente, de acordo com as análises de HERSCHMANN (2010), que destaca a orientação da indústria da música para os grandes concertos ao vivo, a difusão digital e os jogos eletrônicos.

Frente a uma geração que vem se desenvolvendo em meio à era midiática, com uma indústria musical em profunda transformação, com um repertório bastante diversificado, e no qual a música de concerto ocupa um lugar bastante pequeno, como entender o significado dos cursos de História da Música para esses jovens e para o mundo atual? Teria a visão convencional da História da Música também alguma responsabilidade no tipo de evasão do ensino de música em conservatórios, por exemplo, tal como abordado por ESTEVAM (2012)?

O choque entre o título totalizante, mas ao mesmo tempo sua base no repertório europeu de concerto do passado, frequentemente acarreta, nas prioridades e bibliografia desses cursos, a exclusão da música de outras regiões do planeta, da música popular ou tradicional, de quase toda a música ligada ao universo digital ou midiático, e dos repertórios que não se enquadram no fluxo linear geralmente adotado pela bibliografia sobre $o$ assunto. A questão, aqui, não é a importância da música europeia de concerto em si, mas sim a importância que a literatura em questão atribui exclusivamente ou predominantemente a esse repertório, o que gera um inevitável estranhamento por parte de quem não nasceu ou não se formou em um meio social que cultiva exclusivamente ou predominantemente os clássicos.

Tais observações vêm sendo motivo de reflexões de autores internacionais que se dedicam ao tema, a começar pelo questionamento do cânone musical adotado pelas histórias da música (ocidental), como fez BRISCOE (2010). Mas se sabemos disso e em geral percebemos a insustentabilidade dessa visão nos cursos e na bibliografia da atualidade referentes à História da Música, por que frequentemente nos baseamos no mesmo modelo? Esta- ríamos chegando aos limites operacionais dessa reprodução, em função de sua cada vez menor aceitação em sala de aula e da dificuldade cada vez maior de sua manutenção por parte dos docentes?

Considerando-se a expectativa totalizante, percebemos que o título das disciplinas em questão obrigam seus docentes a se esforçarem para abranger o maior número possível de fenômenos musicais, porém com poucas esperanças de resultados satisfatórios, ou, o que é ainda pior, levando-os, às vezes, a defender a História da Música como uma disciplina encerrada no universo eurocêntrico e de concerto. Para oferecer aos estudantes uma disciplina com um título tão amplo, a instituição acaba legando ao docente - mesmo que de forma involuntária - a responsabilidade pelo sucesso ou não de seu título (e não necessariamente de seu conteúdo), ou mesmo das posturas ideológicas assumidas pelo docente em relação ao mesmo.

Fica claro, portanto, que o primeiro problema da referida disciplina está em seu título, pois este gera expectativas não atendíveis, ao passo que seu conteúdo é geralmente limitado e não correspondente aos mesmos. A Etnomusicologia passou por essa mesma necessidade, quando criou esse nome em substituição ao antigo título Musicologia Comparada. Inúmeras outras disciplinas, em várias áreas do conhecimento, vêm fazendo o mesmo, com o propósito de adequação às necessidades do presente e o fenômeno já está atingindo a História da Música em várias partes do mundo.

De fato, o principal sentido acadêmico da História da Música e da História da Música Brasileira está em sua existência enquanto linhas de pesquisa (tanto na Graduação quanto na Pós-Graduação), e não apenas como disciplinas totalizantes. Tais títulos são justificáveis enquanto linhas de pesquisa, porque o desenvolvimento de trabalhos é aberto ao interesse, vivência e decisão dos estudantes/ pesquisadores, o que não ocorre quando tais títulos são aplicados a disciplinas, pois não há como ministrar o conteúdo convencionalmente programado, de forma totalmente aberta a esses mesmos interesses e vivências.

Do ponto de vista histórico, esse problema está relacionado a uma opção ideológica, e não necessariamente aos destinos da história, seja ela no Brasil ou em outras partes do mundo. Até meados 
do século XIX, a circulação da música era um fenômeno vivo: os teatros, igrejas, salões e o próprio ambiente doméstico (sem contar as feiras e mesmo as ruas) eram repletos de composições de autores vivos, muitos dos quais podiam ser encontrados em concertos, eventos e até nos cafés. Com o advento da Belle Époque (cerca de 1860-1920), foi sendo criado um repertório básico de concerto, principalmente com obras de autores mortos, para prover o repertório das orquestras profissionais e do mercado teatral e de discos, que passou a explorar esse tipo de música.

O repertório foi sendo assim padronizado, facilitando seu ensino, promoção e difusão, em um processo semelhante ao que ocorreu com a industrialização de alimentos, de bens de consumo, da arte e da cultura. Excluindo a maior parte da música nova ou contemporânea e a maior parte da música do passado que não interessava a essa visão musical estática e da era industrial, o mercado de concerto não apenas apresentou esse repertório como o tipo de música mais representativo dos grandes teatros, mas subsidiou a construção de "histórias da música" que valorizassem exclusivamente esse repertório. Guardados os excessos e polêmicas, LEBRECHT (2008) demonstra que nem sempre foi o fluxo histórico que determinou os rumos da música de concerto, tendo sido decisivas algumas ações ligadas ao mercado para a implementação de determinados projetos musicais e somente compreensíveis a partir da lógica do mercado.

Do ponto de vista teórico, no entanto, a questão é bem interessante. Em toda a história existiram diversos "círculos" ou "escolas" de compositores e práticas musicais que se relacionavam de distintas maneiras: uns eram antagônicos, outros colaborativos, outros disputavam os mesmos lugares, outros se ignoravam e outros simplesmente conviviam, apesar de suas diferenças. Teoricamente, portanto, podemos dizer que existiram e existem várias "redes" ou mesmo vários "mundos" musicais: o mundo das igrejas, dos clássicos, do rock, do gospel, do choro, do pagode, do jazz, do sertanejo, do folclore, da MPB, das culturas tradicionais, das culturas orientais, da musicologia, da etnomusicologia, etc. Frequentemente, as pessoas de cada um desses mundos exibem roupas, hábitos, alimentações, crenças, interesses, opções de vida e necessidades específicas que não seriam atendidas pelo outro mundo ou rede: um jazzista nem sempre estará satisfeito em um meio sertanejo, assim como um roqueiro não se sentirá plenamente à vontade em um mundo de clássicos: porque são redes ou mundos distintos, embora interligados. A História da Música, no entanto, frequentemente desconsidera os demais mundos e redes, adotando o mundo dos clássicos como o único ou principal a ser estudado na universidade.

Outro fator problemático relacionado ao título dessa disciplina é que, em verdade, a História da Música, tal como normalmente praticada, não é predominantemente uma história, mas sim uma apreciação do repertório musical histórico, na qual se discorre mais sobre as particularidades das obras e dos compositores, do que sobre os aspectos propriamente históricos que levaram à produção de tais repertórios. E isso ocorre justamente porque a apresentação de aspectos principalmente históricos referentes à música do passado não é um assunto e nem uma tarefa natural nos cursos acadêmicos da área de música, nos quais os estudantes estão essencialmente interessados na prática ou criação musical e no conteúdo da música, e não tanto nos debates sobre as razões de sua transformação ao longo do tempo. Quando a bibliografia sobre esse assunto aborda alguns aspectos históricos, a música é, muitas vezes, apresentada como uma sequência cronologicamente organizada de obras ou de compositores, sobre a qual os autores dos livros em questão tecem suas considerações e, muitas vezes, seus juízos de valor.

As consequências práticas da manutenção do antigo modelo da História da Música, particularmente de seu título, são visíveis nas universidades brasileiras: estudantes de vários cursos frequentemente encaram a disciplina apenas como uma das inevitáveis tarefas para se obter o diploma. É corrente, entre eles, utilizar a expressão "eliminar a matéria", para se referir ao ato de cursá-la e ser nela aprovado com o menor envolvimento possível. Por mais que esse quadro seja desanimador aos professores dessa disciplina, pouco adiantará atribuir aos estudantes, sobretudo aos ingressantes, a responsabilidade pelo eventual desinteresse pelos conteúdos em questão, levantando-se aqui a hipótese de que esta seja uma responsabilidade principalmente dos autores dos materiais didáticos, das instituições e dos próprios docentes.

A diminuição do interesse e a perda de significa- 
do do conteúdo das disciplinas de História da Música vem gerando um debate cada vez mais intenso, tanto no Brasil quanto no exterior. A American Musicological Society mantém o Journal of Music History Pedagogy, destinado a publicar artigos sobre as dificuldades enfrentadas por discentes e docentes nessa matéria. $E$ entre os eventos voltados à discussão presencial sobre o assunto são alguns exemplos o I e II Institute for Music History Pedagogy - ciclos de palestras realizados pela Juilliard School of Music (New York, EUA) em 2006 e 2008, destinados a discutir o futuro dessa disciplina - e o debate sobre as atuais dificuldades dos cursos de História da Música ocorridos em alguns eventos brasileiros, especialmente os Congressos Anuais da ANPPOM.

A História da Música, tal como a conhecemos, surgiu em fins do século XVIII (a primeira publicação do gênero que adquiriu notoriedade foi $A$ General History of Music, de Charles Burney, impressa em 1789) e vem mantendo essa designação até o presente. Esse gênero também circula com o título "História da Música Ocidental", que embora assuma a exclusão do Oriente, ao menos substitui as assim denominadas histórias "universais" da música, que apesar do título concentravam-se na música européia e principalmente no Classicismo e Romantismo.

A História da Música, da maneira convencional como vem sendo ministrada, estimula a divisão dos repertórios, instrumentos, comportamentos, culturas e ações enquanto aptas ou não a serem estudadas do ponto de vista histórico. Em uma época na qual são crescentes e cada vez mais necessárias as ações colaborativas para o gerenciamento e o desenvolvimento de populações tão numerosas quanto as da atualidade, a visão linear -evolutiva, positivista e eurocêntrica que predomina na História da Música acadêmica parece cada vez mais fora de seu tempo.

Outro aspecto problemático da História da Música é sua relação com a forma de organização das sociedades atuais. Embora estejamos vivendo em sociedades cada vez mais coletivas, é comum encontrar, na bibliografia convencional dessa disciplina, um discurso baseado na ação de indivíduos (compositores), quando, na prática, observamos dois aspectos interessantes: 1) Somente do século XVI a início do XX (com apogeu no século XIX) a prática musical foi centralizada na decisão dos compositores, uma vez que nos períodos anterior e posterior o compositor deixou de ser o personagem principal do mundo da música e frequentemente tornou-se um servidor de instituições mais influentes que os mesmos; 2) Apesar da prática musical da atualidade não ser mais predominantemente movida por compositores, a bibliografia do gênero ainda os apresenta como os propulsores da música do presente, o que estimula visões e posicionamentos um tanto ilusórios por parte dos estudantes, que não serão correspondidos na prática, ao menos fora do âmbito acadêmico. Tanto na música medieval quanto na era industrial, não foram os compositores que decidiram os rumos da música, mas sim as instituições às quais estes se ligaram: na Idade Média muitos serviam à igreja, enquanto na atualidade vários atuam em gravadoras, agências de publicidade, empresas cinematográficas, redes de TV e mesmo universidades.

A bibliografia convencional de História da Música é muito enfática na construção de um discurso linear baseado não apenas na depuração e aperfeiçoamento da música, mas principalmente na constituição de um fluxo caracterizado pela competição e pela disputa entre autores, músicos, estilos e gêneros, dos quais venceram os melhores e mais fortes. Por outro lado, é mesmo difícil conceber uma atividade que seja tão colaborativa quanto a música - como ressaltam BARENBOIM e SAID (2003) -, que, além dos músicos, regentes e compositores, envolve os produtores, os teatros e igrejas (e suas religiões), a imprensa, os governos e o próprio público, na busca por um interesse comum, sem o qual as apresentações musicais não acontecem e nunca teriam acontecido.

Na prática, e por muitas razões, o conteúdo dos cursos de História da Música não é muito usado pelos musicistas egressos dos conservatórios e universidades, mesmo tendo frequentado tais disciplinas por três ou quatro anos consecutivos, sendo cada vez mais raros os programas de concerto, as explicações ao público, os projetos artísticos e a circulação de informações históricas associadas à prática musical. $\mathrm{O}$ que é efetivamente e justamente manifesto é o interesse dos músicos e dos ouvintes pela música em si, pela vivência que dela decorre, o desejo do sucesso, do reconhecimento e da relação positiva com o público, embora muitas vezes e infelizmente esta se resuma à busca por celebridade e reconhecimento exclusivamente pessoal. 
Não é difícil constatar que os profissionais da área da Música interessam-se e desenvolvem ações relacionadas a instrumentos, grupos vocais e instrumentais, sonoridades, repertórios, ideias, gêneros e estilos, e não necessariamente pelas circunstâncias sociais, econômicas, políticas e culturais que originaram a música do passado. Os profissionais que se interessam efetivamente pela história e desenvolvem eficientes ações e pesquisas de qualidade a ela relacionadas são os historiadores, que possuem formação, métodos, bibliografia e estratégias intelectuais bem mais ricas e sofisticadas do que as que temos na área de música.

Na época em que foi criada a História da Música, no auge do lluminismo, acreditava-se que a história era o principal atributo que levava à excelência do repertório, filtrado por séculos de suas impurezas e aperfeiçoado de geração em geração, rumo ao progresso, como já observou LUCAS (1998). A partir dessa visão, surgiu, para o estudo panorâmico de diversas disciplinas, a ideia de que construir sua história seria a melhor solução para entender os seus propósitos. Nasceram assim a história das ciências, a história das religiões, a história das nações, a história das artes e muitas outras, com a esperança de que proporcionassem uma relação eficiente com o volumoso legado de todas elas. Mas um dos problemas decorrentes foi o aprisionamento às práticas e repertórios nelas representados e a tendência à exclusão das práticas e repertórios não representados.

Uma análise da bibliografia adotada nos cursos de História da Música demonstra que a maioria dos compêndios não se refere exatamente à música "universal", ocidental ou mesmo europeia, já que a grande maioria do repertório europeu externo aos teatros - como as obras religiosas (especialmente não-cristãs), populares e folclóricas - não é incluída nessa literatura. $O$ que as histórias acadêmicas da música principalmente apresentam é a história do mercado da música de concerto (e de suas gravações em áudio e vídeo), baseada em um repertório de autores do passado europeus (recentemente também de autores norteamericanos), e de música destinada ou usável em teatros e gravações.

Diferentemente do que ocorre em outras modalidades de história, a História da Música está muito ligada à preparação do público de concerto e de gravações ou material relacionado a esse repertório. Era uma oportunidade para que o público inte- ressado soubesse mais sobre as peças que apreciava, para conhecer obras com as quais ainda não havia tido contato. Mas, embora tenha sido inicialmente destinada ao público e não aos músicos profissionais, acabou sendo adotada nos cursos acadêmicos, por ser uma das poucas disciplinas panorâmicas disponíveis sobre a música estudada nessas instituições. Se esse tipo de literatura cumpriu uma função importante junto aos profissionais da área de Música até meados do século $X X$, isso vem ocorrendo de forma cada vez menos intensa.

A forte ligação da História da Música convencional com o público dos "clássicos" é uma das razões da concentração dessa literatura na música que circula nos teatros e nos discos dessa categoria. Por essa razão, são apresentados como externos a essa literatura os repertórios populares ou folclóricos e de origem não-europeia, os significados sociais de seu uso na atualidade e mesmo os reais motivos que levaram o público e os compositores a abandonarem os repertórios mais antigos em nome dos mais recentes. Afinal, se a vanguarda do século $X X$ negou-se a compor música como no passado, como explicar, em termos históricos, as razões da existência desse mesmo repertório do passado nas salas de concerto e no mercado fonográfico?

Diante do exposto, o que pode ser feito para produzir uma relação mais saudável e eficiente com a herança musical recebida das gerações e dos séculos que nos antecederam? É necessário, para uma boa relação com a música, que compreendamos todas as suas razões sociais, econômicas, políticas e culturais, além da obrigação de memorizar informações sobre estilos, compositores, gêneros musicais e repertórios, mesmo que nosso propósito não seja esse? E será que esse estudo nos coloca em contato, de forma eficiente, com as grandes questões sociais, econômicas, políticas e culturais da atualidade, que efetivamente teremos que encarar no decorrer de nossas carreiras?

\section{Música, História, Cultura e Sociedade}

A ideia de que a História da Música convencional prepara os profissionais da área da música para um contato amplo com o repertório com o qual irão trabalhar talvez já não tenha tanta aplicação no presente. Atualmente essa visão não somente se 
mostra enfraquecida, como dificulta uma função mais eficiente da música em uma sociedade mais complexa e diversificada. Por essa razão, parece mais eficaz dar menos espaço ao estudo histórico (sobretudo linear) da música do passado e mais às suas funções e formas de utilização na atualidade, bem como às contínuas transformações que as obras do passado receberam após sua composição. Para citar um único exemplo, frequentemente estudamos Bach no século XVIII, mas não damos tanta ênfase às reelaborações de sua obra no século XIX ou à sua popularização por meios eletrônicos no século $X X$.

Afinal, se a História da Música (enquanto linha de pesquisa) estuda as transformações da música ao longo da história, considerando-as como adaptações às mudanças sociais, culturais, políticas e econômicas, por que não aplicamos esse mesmo pensamento à disciplina História da Música, que vem se modificando de forma bem menos intensa, mesmo após atravessar períodos de profundas mudanças sociais quanto os que ocorreram no século XX?

Com a crescente diversidade cultural, de interesses, vivências e propostas dos estudantes, que se acentuará ainda mais com o desenvolvimento econômico brasileiro, com o crescimento populacional e, sobretudo, com o impacto dos sistemas de cotas de ingresso em algumas universidades, torna-se cada vez mais difícil a adoção de visões únicas e de disciplinas de conteúdo totalizante no título porém não no conteúdo.

O assunto não é novo no meio acadêmico-musical brasileiro e, em algumas das discussões em eventos ou nas próprias universidades, alguns colegas manifestam a preocupação de que mudanças nessa disciplina causariam a perda de conteúdo importante aos estudantes. Essa possível perda obviamente não é real, uma vez que nunca houve tanta informação em livros, artigos, filmes e áudio gratuitamente disponíveis aos interessados quanto na atualidade. $O$ temor em questão talvez esteja menos relacionado à eventual perda de conteúdo, e mais à transformação da antiga função docente, de transmissão do conhecimento pessoal para a de facilitadores do acesso ao conhecimento público e disponível a um número cada vez maior de pessoas.
De fato, existem cursos completos de História da Música convencional gratuitamente disponíveis em vídeo no Youtube, no Vimeo, na Open University, na iTunes U, no TED/ldeas Worth Spreading, na TV Escola e na Univesptv/Unesp, estando disponível, nesta última, um dos cursos completos de História da Música II ministrado por Dorotéa Machado Kerr no Instituto de Artes da UNESP², com uma média, neste momento, de mais de mil visualizações por episódio e quase 18 mil visualizações somente do primeiro deles, menos de um ano após a postagem, o que demonstra que os estudantes realmente consultam esse tipo de material na internet. A série História da Música Brasileira $^{3}$, que produzi em colaboração com Ricardo Kanji e Ricardo Maranhão em 10 episódios (1999), já está com uma média de 5 mil visualizações por programa no Youtube e quase 30 mil visualizações do primeiro deles, apenas dois anos após a postagem. A série de áudios Alma Latina ${ }^{4}$, sobre a música nas Américas do século XVI a inícios do XIX, conta com quase mil downloads, um ano após a postagem, sem contabilizar as audições online, provavelmente bem mais numerosas. Vários blogs estão disponibilizando um número cada vez maior de documentários em vídeo e áudio sobre o assunto, como Corpo, Som e Movimento, de Pedro Consorte, com mais de 60 documentários em vídeo sobre música brasileira (popular ou de concerto), disponíveis gratuitamente. ${ }^{5}$

Em âmbito internacional, a quantidade desses vídeos e de suas visualizações é surpreendente e vem aumentando a cada ano. A "Historia de la Música - Lecciones llustradas", de Pablo Morales de Los Rios ${ }^{6}$, por exemplo, já ultrapassou 350 mil visualizações, um ano e meio após sua postagem. No site Open Culture ${ }^{7}$, que já conta com mais de 280 mil "curtir" no Facebook ${ }^{8}$, existem vários documentários sobre música disponíveis, entre os mais de 750 documentários gratuitos em vídeo, referentes aos mais diversos assuntos. Tenho reunindo, em meu próprio blog ${ }^{9}$, endereços de dezenas de websites com material semelhante, os quais disponibilizam gratuitamente farta quantidade de informações, textos, gravações, partituras, facsímiles de manuscritos e musicais e edições antigas, imagens, iconografia, dicionários, enciclopédias, textos históricos, tratados e outros links, que permitem o livre acesso dos interessados a esse tipo de material. 
A perda de conteúdo não é, portanto, um perigo associado às transformações dos cursos de História da Música. O fato é que os interessados nas Histórias da Música convencionais já não dependem tanto de professores para sua transmissão, mas sim de uma boa relação com as livrarias, com as bibliotecas e com a internet. A função dos docentes e estudantes nas instituições de ensino (ou, digamos, a relação entre eles) está em rápida mudança na atualidade, mas nem sempre conseguimos adaptar nossos cursos a essas novas relações.

Um dos desafios atuais em disciplinas de âmbito geral ou panorâmico é, portanto, oferecer a capacitação para a solução de problemas de âmbito geral, porém aberta a quaisquer decisões, escolhas, tendências e aptidões particulares dos estudantes. A tarefa é complexa, porém não está desamparada: a bibliografia atualmente disponível na área de música (mesmo em português) possui muitos títulos voltados a essa questão, em quantidade geralmente maior do que a bibliografia convencional sobre História da Música. Paradoxalmente, utilizamos menos essa bibliografia atual nos cursos acadêmicos dessa disciplina e preferimos manter os livros convencionais (geralmente europeus ou norteamericanos) e cultivar uma relação frequentemente discursiva e descritiva da música do passado, principalmente a europeia.

Na prática, experiências mais abertas do que as propostas pelos cursos de História da Música já existem em várias instituições brasileiras. Disciplinas e linhas de pesquisa intituladas "Arte, Cultura e Sociedade", "Arte, Música e Sociedade", "Música, Cultura e Sociedade", "História, Cultura e Sociedade" e outras, existem em várias universidades brasileiras, em nível de graduação e pós-graduação. "História e Música" (repare a substituição do DA por E) é o nome da atual disciplina do Curso de Graduação em Música da Escola de Música da UFMG, que substituiu as antigas "Histórias da Música" e várias instituições estão estudando mudanças nessa direção. "Música, História, Cultura e Sociedade" é, portanto e no mínimo, uma forte tendência atual, apesar das variações no título, valendo a pena refletir sobre sua aplicação nos cursos que ministramos em nossas universidades.

\section{Ser autor e professor, em disciplinas obriga- tórias e optativas}

Se o conhecimento oferecido pelas instituições acadêmicas ficar circunscrito às disciplinas obrigatórias, uma parte considerável das turmas de estudantes sempre ficará insatisfeita e, consequentemente, desinteressada pelos assuntos oficiais ministrados em cada uma delas. A oferta de disciplinas obrigatórias de conteúdo geral, aliado ao oferecimento de disciplinas optativas de conteúdo específico é uma solução bastante rica para a crescente diversidade de práticas e interesses manifesta pelos estudantes brasileiros da área de Música.

Esse tipo de procedimento é comum em muitos cursos universitários no exterior. Em Portugal, por exemplo, os cursos possuem dois grupos de disciplinas, divididas (como é o caso da Universidade Nova de Lisboa) em "obrigatórias" e "opção condicionada", com um número mínimo de disciplinas a serem escolhidas. $\mathrm{Na}$ Inglaterra, entre os muitos exemplos interessantes, a School of Music at the University of Leeds possui dois grupos de disciplinas, divididas em "Compulsory Modules" e "Optional Modules", não mais existindo, no primeiro deles, a antiga "History of Music", mas sim "Music in History and Culture", título também adotado em várias outras universidades de países de língua inglesa.

Nós, professores brasileiros, com raras exceções, não temos suficiente produção autoral no campo da história da música europeia para ser integrada aos compêndios de História da Música usados nos cursos acadêmicos da área. Os livros brasileiros do gênero - novamente com raras exceções - são principalmente baseados em informações secundárias, muitas vezes obtidas em outras Histórias da Música, acrescidas da apreciação de novas partituras e gravações, e escritas com uma linguagem mais adaptada ao nosso meio musical do que as obras simplesmente traduzidas de outros idiomas.

Temos, sim, produção significativa para a História da Música Brasileira (ou no Brasil), mas tal produção não tem sido convertida em compêndios para o estudo dessa disciplina e os títulos mais abrangentes à disposição são obras do século $X X$, já defasadas do conhecimento produzido nas últimas décadas. Por que não observamos a produção de 
versões atuais de Histórias da Música Brasileira, apesar de ensinarmos essa disciplina há algumas décadas no país? E como compreender o ensino da História da Música (ocidental ou europeia) sem que sejamos majoritariamente autores nesse campo? Haveria alguma maneira de fazermos mudanças no título e no conceito dessa disciplina, que favorecessem a possibilidade de nos tornarmos, simultaneamente, professores e autores do que ensinamos?

Uma das possibilidades é transformação da antiga "História da Música" em uma disciplina de título (ou ao menos de conteúdo) mais amplo, que privilegiasse mais a complexidade da música atual e os assuntos dos quais temos maior vivência, controle e possibilidade de autoria, como "Música, História, Cultura e Sociedade" ou títulos similares, mais abertos aos fenômenos do presente e às necessidades do mundo atual, como já vem propondo CAESAR (2012). Assim, poderíamos deixar as questões mais gerais e que permitissem uma compreensão ampla de nossa relação com o passado musical em disciplinas gerais e obrigatórias, ficando os assuntos específicos para disciplinas eventuais ou optativas.

Seria um curso sobre a música romântica, por exemplo, melhor ministrado por um professor generalista, que muitas vezes não teve um contato orgânico com esse repertório em função do instrumento ao qual se dedicou, ou por um pianista, regente ou músico de orquestra, cuja atuação profissional foi baseada nesse tipo de música? Não é um problema o fato de que os docentes em questão não possuam treinamento no campo da história, pois não é esse o aspecto mais explorado nessa disciplina e nem o que mais interessa aos estudantes, mas sim o contato com a lógica desse repertório, com seu significado, com as meIhores maneiras para sua execução, seus autores e obras. Paralelamente, um curso sobre a música sacra brasileira do século XVIII ou sobre o patrimônio histórico-musical brasileiro funcionaria bem melhor para alunos que tenham interesse específico nesses assuntos, do que ministrado a todos os alunos em disciplinas obrigatórias, entre os quais haverá uma parte considerável sem relações pessoais com os temas referidos.

\section{A urgência de uma reforma curricular volta- da às necessidades atuais}

É cada vez mais difícil, para as condições nas quais vivemos na atualidade, imaginar que cursos e conteúdos fixos atenderão às necessidades de todos, e que caberá exclusivamente a alguns profissionais resolver os problemas decorrentes das diferenças entre o ensino recebido e as possibilidades profissionais no mercado de trabalho. $O$ mercado de trabalho está em constante transformação e nunca passou por mudanças tão intensas quanto as que presenciamos na atualidade, com a extinção de corpos "estáveis", fechamento de teatros e cinemas, intensa transformação da indústria da música, privatização direta ou indireta de órgãos públicos que apóiam a música de concerto e brutal massificação cultural imposta pela mídia, com acentuadas e constantes mudanças (voluntárias ou involuntárias) de interesse por parte dos receptores ou consumidores de música, no Brasil e em todo o mundo.

Obviamente, esse quadro suscita, por parte de alguns colegas, a exclusiva abordagem do repertório de concerto como uma forma de defesa contra as transformações impostas pelo mercado da atualidade. Essa postura, contudo, poderia até criar um ambiente interno favorável à música de concerto, porém não serviria como real preparação para o mercado de trabalho, que não está mais tão baseado na música de concerto quanto esteve no passado. Mesmo assim, tal visão não atenderia os estudantes interessados e muitas vezes praticantes de outras concepções musicais, cujo número é cada vez maior nas universidades públicas. Uma solução possível, na atualidade, parece ser a adoção da diversidade de opções, frente à diversidade de interesses e práticas dos estudantes, solução que faz sentido para o corpo discente e evita a visão única praticada nos currículos acadêmicos da área de música e especialmente nos cursos de História da Música. Não necessitamos apenas de reformas curriculares para adequar as antigas disciplinas aos novos tempos, precisamos de disciplinas diferentes e de novas abordagens, para estudantes de um novo tempo, que não são mais atendidos e nem eficientemente preparados por disciplinas e métodos convencionais. 


\section{Conclusões}

Pelas razões apresentadas, uma das primeiras tarefas em relação a este assunto, a meu ver, é a mudança ou ampliação do título das disciplinas de História da Música, o que evitaria, de antemão, as expectativas totalizantes, o temor pela abordagem exclusivamente histórica e a aversão pelo repertório exclusivamente europeu, fatores que limitam o aproveitamento e dificultam a obtenção de resultados mais eficientes dos cursos. "Música, História, Cultura e Sociedade" é uma possibilidade mais aberta e não-linear, que permite uma abordagem mais ampla e relacionada aos interesses e atividades dos estudantes, sendo outras tarefas o aumento da oferta de disciplinas optativas, o aumento da diversidade na abordagem da disciplina e o maior engajamento dos docentes na autoria dos textos históricos, e não somente na adoção da literatura disponível.

Essa mudança não visa excluir o conteúdo da convencional História da Música que ainda nos possa interessar, mas apenas flexibilizá-lo e conectá-lo mais intensamente com os estudantes da atualidade, de uma forma mais ampla, menos direcionada e mais aberta às possibilidades, aos hábitos, aos interesses e às projeções dos alunos. Seu caráter geral e sua conexão com os estudos específicos (em disciplinas optativas) permitiriam uma recepção mais orgânica das matérias e contribuiriam para uma interação mais efetiva e transformadora por parte dos estudantes, além de um envolvimento autoral mais intenso por parte dos docentes.

\section{Notas}

1. Consultar os demais relatórios em: http://www. abpd.org.br/.

2.https://www.youtube.com/playlist?list=PLB11EEBBD5514D1DA

3. https://www.youtube.com/HistoriadaMB

4. http://archive.org/details/AlmaLatina

5.http://pedroconsortebr.wordpress. com/2012/10/30/documentarios-sobre-a-musica -brasileira-lista-completa/

6. http://youtu.be/ImqEJHsUm3I

7.http://www.openculture.com/freeonlinecourses
8. https://www.facebook.com/openculture

9. http://paulocastagna.com/ alma-latina

\section{Referências Bibliográficas}

ASSOCIAÇÃO BRASILEIRA DOS PRODUTORES DE DISCOS. Mercado brasileiro de música 2012. Rio de Janeiro: ABPD, 2012. 7p.

BARENBOIM, Daniel \& SAID, Edward W. Paralelos e paradoxos: reflexões sobre música e sociedade; tradução de Hildegard Feist. São Paulo: Companhia das Letras, 2003. 188p. ISBN: 85-3590427-1; ISBN-13: 978-85-359-0427-7.

BRISCOE, James R. Vitalizing Music History Teaching. Hillsdale: Pendragon Press, 2010, 202p. (Monographs and Bibliographies in American Music, v.20) ISBN: 978-1-57647-162-3.

CAESAR, Wesley. Música (cultura e sociedade): introdução ao estudo geral da música. São Paulo: Scortecci, 2012. ISBN: 978-85-366-2500-3. 245p.

ESTEVAM, Vicente. Evasão no ensino de música em conservatórios. São Paulo: Curitiba: Appris, 2012. 220p. ISBN: 85-819-2112-4. ISBN-13: 97885-819-2112-9.

HERSCHMANN, Micael M. Indústria da música em transição. Rio de Janeiro: Estação das Letras, 2010. 184p. ISBN: 8560166378. ISBN-13: 978-85601-6637-4.

LEBRECHT, Norman. Maestros, obras-primas e loucura; tradução Rafael Sando. São Paulo: Record, 2008. 350p. ISBN: 85-010-7763-1. ISBN-13: 978-85-010-7763-9.

LUCAS, Maria Elisabeth. Perspectivas da pesquisa musicológica na América Latina: 0 caso brasileiro. I SIMPÓSIO LATINOAMERICANO DE MUSICOLOGIA, Curitiba, 10-12 jan. 1997. Anais. Curitiba: Fundação Cultural de Curitiba, 1998. p. 69-74.

\section{Sobre o autor}

Paulo Castagna (paulocastagna.com/) é Graduado e Mestre pela Escola de Comunicações e Artes da USP na área de Música e Doutor pela Faculdade de Filosofia e Ciências Humanas da USP na área de História, com Estágio Pós-Doutoral na Universi- 
dad de Jaén (Espanha). Foi bolsista do CNPq, da Funarte, da Fapesp e da Fundação Vitae, sendo atualmente pesquisador do $\mathrm{CNPq}$, na categoria Produtividade. É docente e pesquisador do Instituto de Artes da Unesp desde 1994, onde exerce a vice-coordenação do Programa de Pós-Graduação em Música e a coordenação do NOMO乏 - Núcleo de Musicologia Social do Instituto de Artes da Unesp. Vem produzindo partituras, livros e artigos na área de musicologia histórica, além de cursos, conferências, programas de rádio e televisão, coordenando encontros de musicologia e a pesquisa musicológica para a gravação de CDs. Coordenou a Equipe de Organização e Catalogação da Seção de Música do Arquivo da Cúria Metropolitana de São Paulo (1987-1999), a Equipe Musicológica do projeto Acervo da Música Brasileira / Restauração e Difusão de Partituras no Museu da Música de Mariana (Fundarq/Santa Rosa Bureau Cultural/Petrobras, 2001-2003) e o projeto Patrimônio Arquivístico-Musical Mineiro (Secretaria de Estado da Cultura de Minas Gerais, 2007-2011). Entre os projetos recentes estão a coordenação do XXIV Congresso da Anppom (Associação Nacional de Pesquisa e Pós-Graduação em Música), a criação do E-mhics1 (I Encontro de Música, História, Cultura e Sociedade do Vale do Paraíba) e o DiverSampa: um passeio pela diversidade sonora, cultural, histórica, religiosa e urbanística da região central de São Paulo. 